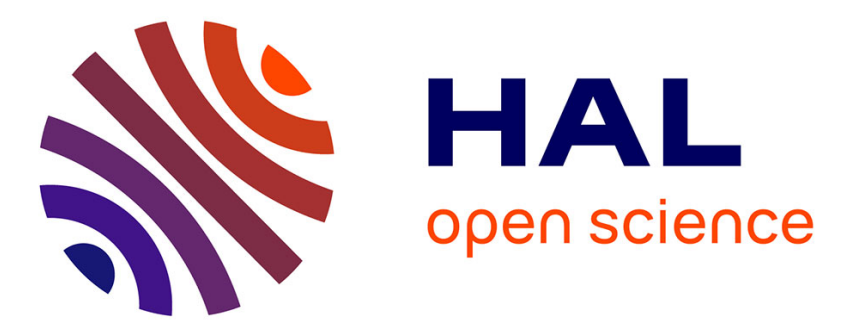

\title{
An Observation of Electron Density Distribution of $\mathrm{Fe} 3 \mathrm{O} 4$
}

\author{
Y. Kino, K. Yamamoto, F. Okamura, K. Shiratori
}

\section{To cite this version:}

Y. Kino, K. Yamamoto, F. Okamura, K. Shiratori. An Observation of Electron Density Distribution of Fe3O4. Journal de Physique IV Proceedings, 1997, 07 (C1), pp.C1-587-C1-588. 10.1051/jp4:19971241 . jpa-00254927

\section{HAL Id: jpa-00254927 https://hal.science/jpa-00254927}

Submitted on 1 Jan 1997

HAL is a multi-disciplinary open access archive for the deposit and dissemination of scientific research documents, whether they are published or not. The documents may come from teaching and research institutions in France or abroad, or from public or private research centers.
L'archive ouverte pluridisciplinaire HAL, est destinée au dépôt et à la diffusion de documents scientifiques de niveau recherche, publiés ou non, émanant des établissements d'enseignement et de recherche français ou étrangers, des laboratoires publics ou privés. 


\title{
An Observation of Electron Density Distribution of $\mathrm{Fe}_{3} \mathrm{O}_{4}$
}

\author{
Y. Kino, K. Yamamoto*, F. Okamura** and K. Shiratori*** \\ X-ray Research Laboratory, RIGAKU Co., Akishima, Tokyo 196, Japan \\ * Department of Physics, University of Nara womens, Nara 630, Japan \\ ** National Institute for Research in Inorganic Materials, Tsukuba, Ibaraki, 305 Japan \\ *** Department of Physics, University of Kyushu, Fukuoka 812-31, Japan
}

\begin{abstract}
Magnetite, $\mathrm{Fe}_{3} \mathrm{O}_{4}$, is a typical magnetic oxide with so called Verway transition at $124 \mathrm{k}$. Its properties are very interesting in terms of magnetism, electric conduction, crystal phase transition, etc. While much thorough research has been done on $\mathrm{Fe}_{3} \mathrm{O}_{4}$, a new experimental approach is needed. In order to obtain the electron density map with detail, a measurement of a lot of Bragg reflections is critical and hence the shortest w avelength is highly required.

We have developed an $X$-ray generator of $W k \alpha(\lambda=0.20889 A)$ radiation for this purpose and also, found the combination of the Wka diffraction and Maximum Entropy Method (MEM) analysis produces a good result in obtaining not only the crystal structure but also the structure at the electron level. We have observed 615 reflections including one of index $(\mathrm{hkl}):(3684)$ at the highest diffraction angle at room temperature. We observed the maps of the electron density distribution of the (100) and (110) planes of $\mathrm{Fe}_{3} \mathrm{O}_{4}$ in detail and also the 3d-localized electron density distribution corresponding to the d orbital..
\end{abstract}

\section{Introduction}

$\mathrm{Fe}_{3} \mathrm{O}_{4}$ is a typical magnetic oxide which has spinel type crystal structure. Its properties are very interesting in terms of magnetism, electric conduction and crystal phase transition. While much thorough research has been done on $\mathrm{Fe}_{3} \mathrm{O}_{4}$, a new experimental approach is needed. A measurement of crystal structures on the electron level was carried out by the MEM software program analyzing the data of diffraction with short wavelength (Wko). 'This experimental approach seems to be novel and it was quite good to learn the electron structure. We have observed 615 Bragg reflections up to the index (hkl):(36 84 ) of $\mathrm{Fe}_{3} \mathrm{O}_{4}$ at room temperature and obtained the maps of the electron density distribution of the (100) and (110) planes in detail. And then, we further advanced the MEM analysis and found the sharp peaks corresponding to the localized electrons of the 3d orbital.

\section{Experimental Procedures}

An already well known fact is the possibility of generating short wavelength characteristic X-ray from heavy elements such as $\mathrm{W}, \mathrm{Pt}, \mathrm{Au}, \mathrm{Th}$ and $\mathrm{U}$ by using in-lab. X-rays. In practice, however, this has hitherto been virtually impractical because several improvements on the conventional techniques would be necessary. For instance, the excitation voltage for characteristic X-ray radiation is $69.3 \mathrm{kV}$ with W and $115 \mathrm{kV}$ with $\mathrm{U}$. In order to obtain a more detailed electron density distribution, much shorter wavelength of X-ray radiation is highly required. We have newly developed a rolating-anode $X$-ray radiation of the $W \mathrm{k} \alpha(\lambda=0.208892 \mathrm{~A})$ on $200 \mathrm{kV}$ and max. $90 \mathrm{~mA}$ which is the shortest wavelength for in-lab. X-ray diffractometer.

Recent works of the MEM were reviewed by M.Sakata et al. Here, we introduce information entropy, S. The unit cell is divided into $\mathrm{NxN}_{x N}$ pixels. $\rho$ i the electron density at the pixel $\mathrm{i}$, is deduced by maximizing the entropy which is as

$$
\mathrm{S}=\Sigma \rho_{\mathrm{i}}(\mathrm{r}) \ln \rho_{\mathrm{i}}(\mathrm{r}) / \mathrm{m}_{\mathrm{i}}(\mathrm{r})
$$

where $\rho_{i}(r)$ and $m_{i}(r)$ as $\rho_{i}(r)=\rho_{i}(r) / \Sigma \rho_{i}(r)$ and $m_{i}(r)=\tau i(r) / \Sigma \tau_{i}(r)$, respectively. In the absence of any added information, the entropy, $\mathrm{S}$ is maximum when $\rho(x)$ is $\mathrm{m}_{\mathrm{i}}(\mathrm{r})$ for all $\mathrm{i}$. Henceforward, the information entropy related to the electron densities by these equation. While $\rho_{\mathrm{i}}(r)$ is a new electron density, $\tau \mathrm{i}(\mathrm{r})$ is a prior uniform electron density. In order to derive the MCM equation, the entropy term and the following equation (2) of the constraint term is combined by using Lagrange equation,

$$
\mathrm{C}=1 / \mathrm{N} \Sigma\left\{\mathrm{F}_{\mathrm{obs}}(\mathrm{h}) \mathrm{F}_{\mathrm{cal}}(\mathrm{h})\right\} \quad 2 / \sigma(\mathrm{h})^{2}
$$


here $\sigma(h)$ is the standard deviation of the observed $F_{\text {obs }}(\mathrm{h})$. This equation is expected to be 1 while we are taking the correct $\mathrm{F}_{\text {obs }}$ and $\mathrm{F}_{\mathrm{cal}}$ of structure factors. When we are making of maximization of the entropy, it can be understood naturally that the electron distribution in the most ambiguous state are represented as a solution of the MEM within the error of measured data

The sample is a sphere of $0.86 \mathrm{~mm}$ in diameter prepared from an $\mathrm{Fe}_{3} \mathrm{O}_{4}$ single crystal, which was grown in sealed air at $1640 \mathrm{C}$ by the Bridgeman method. The observed value(Fobs) obtained with 4-circle X-ray diffractometer compared with calculated value (Fcal). R-factor was below $1 \%$ and the agreement between the observed value and calculated value proved to be good. 615 Bragg reflections up to the index (hkl):(36 84$)$ were observed.

\section{Results and Disscussion}

Fig. 1 shows the electron density distribution of the (110) plane of Fe3O4. There is a bonding electron peak on the line connecting the oxygen and $\mathrm{Fe}^{3+}$ ion at the tetrahedral site(8a-site). This is corresponding to the covalent bond. The electron density distribution of $\mathrm{Fe}^{2+}, \mathrm{Fe}^{3+}$ ions at the octahedral site(16d-site) and oxygen is linked by the outer electron cloud to be the ionic bond, appearing somewhat weaker than the covalent bond at 8 a-site..

In Fig. 2 and Fig. 3 of the (110) plane and (100) plane, respectively, software program analysis of MEM can show the electron density distribution after the electron density of inner-shell electrons(core electrons) is subtracted. The contour line is drawn in a more minute way, at interval of $0.1 \mathrm{e} / \mathrm{A}^{3}$. In Fig. 2, thexe is a electron density peak on the line connecting the oxygen and $\mathrm{Fe}^{3+}$ ions at the 8a-site which is corresponding to the covalent bond. And also, there are two sharp peaks on both proximate sides of the center of the $\mathrm{Fe}^{3+}$ ions at the $8 \mathrm{a}$-site and $\mathrm{Fe}^{2+}, \mathrm{Fe}^{3+}$ ions at the $16 \mathrm{~d}$-site. These peaks seem to be due to $3 \mathrm{~d}$ localized electrons. It is considered to be the electron in d $\gamma$ orbital of low energy state of $3 d$ localized electrons, spreading in the direction of the space, not in the oxygen direction at the $8 \mathrm{a}$-site. And also, at $16 \mathrm{~d}$-site, it is considered to be the electron in $\mathrm{d} \gamma$ orbital of high energy state of $3 d$ localized electrons, spreading in the oxygen direction.

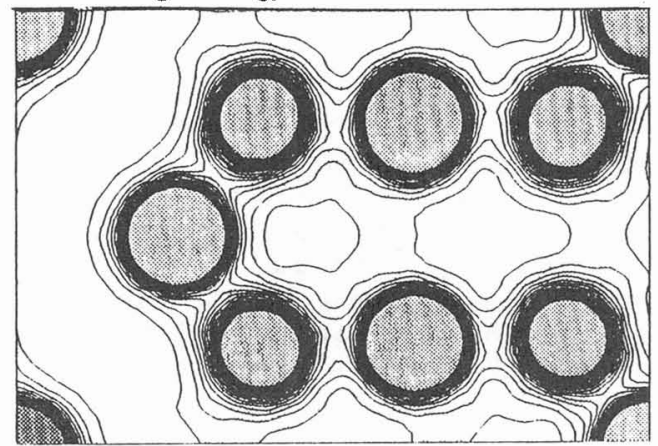

Fig1.; The electron density distribution of $\mathrm{Fe}_{3} \mathrm{O}_{4}(110)$ plane obtained by the MEM analizing the data by Wka $\mathrm{X}$-ray diffractometer. Contour lines are drawn at interval of $0.15 \mathrm{e} / \mathrm{A}^{3}$.

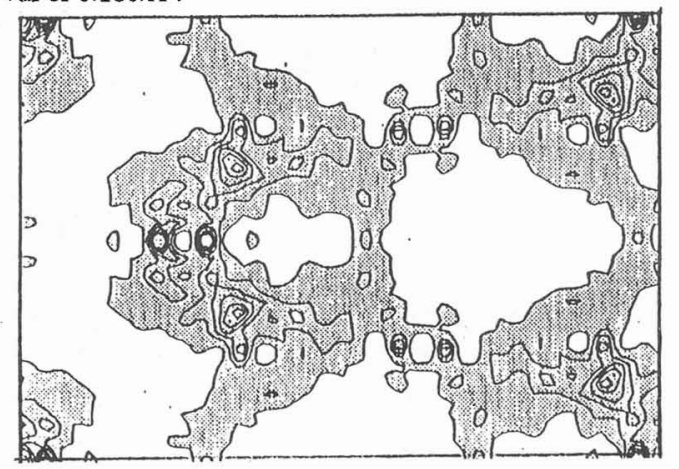

(110) plane sfter the electron density of innershell electrons is subtracted. The contour lines are drawn at interval of $0.1 \mathrm{e} / \mathrm{A}^{3}$.

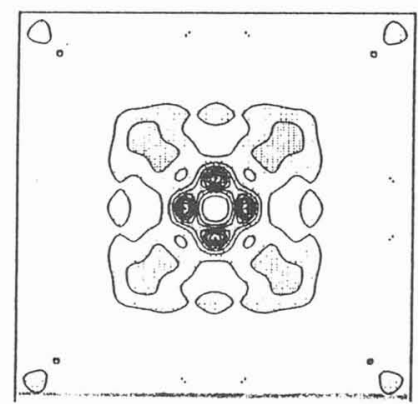

Fig3.; The electron density distribution of $\mathrm{Fe}_{\theta_{3} \mathrm{O}_{4}}$ (100) plane after the electron density of inner-shell electrons is subtracted.

\section{Acknowledgment}

We gratefully acknowledge H. Takahashi for sphere sample preparation. This work is supported by the Japan Electric Industry Development Association. References

1) K.Shiratori and Y.Kino; J.Mag. Mat. 20 (1980) 87

2) M.Sakata and N. Sato; Acta Cryst.A46 (1990)263

3) K.Yamamoto et al; Solid State lonics 48 (1991) 241

Fig. 2; The electron density distribution of $\mathrm{Fe}_{3} \mathrm{O}_{4}$ 